\title{
Neural Network Structure PID Control of Power System for Hydraulic Walking Platform
}

\author{
WANG Jun ${ }^{1 \mathrm{a}}$, JIN Yi ${ }^{1 \mathrm{~b}}$, ZHANG Zhi-yuan ${ }^{1 \mathrm{c}}$ \\ ${ }^{1}$ Department of Mechanical Engineering, Academy of Armored Forces Engineering, Beijing \\ 100072,China \\ ajoe4126@163.com, bjinyi@163.com, chzhiyuanzhang@163.com
}

\begin{abstract}
Keywords: PID, Neural network, Power system, Hydraulic walking platform
Abstract. To meet the control demand of power system in for hydraulic walking platform, based on the brief analysis of digital PID structure and its shortcoming, fast regulation and control precision control for requirement of power system is given, control algorithm for neural network structure PID is presented, control strategy of closed-loop control is made. Control algorithm and effect of control system is verified in experimental bench, experimental results showed that neural network structure PID algorithm effect is stable and it can meet the adjusting requirement in transient speed.
\end{abstract}

\section{Introduction}

Combined with many technologies of articulation mechanism, hydraulic pressure transmission, electronic control and intelligent contro[1], hydraulic walking platform formed by four-legged robot can finish different task in the harsh condition, it plays an important role in emergency and disaster saving. In order to make rapid response for the gait change and work for long time in the wild condition, power system of high power density and flexible control is needed, since there are some advantages of large torque and easy control in variable bump, and small volume, easy starting in gasoline engine[2], small type gasoline engine and variable bump are selected to form power system. Control algorithm is a key part to quickly regulate rotation speed of engine for transient load change, for self-adapt control of more variable profile, PID algorithm is a common method to control gasoline throttle, there were technical materials about PID control for gasoline in periodical and some reports. Among these materials, PID coefficient self-tuning is a research key point based on model or rule, Liu Dao put through PID coefficient self-tuning by improved particle swarm optimization algorithm, it simplified calculation of PID coefficient self-tuning[3]. Li Rui xia presented PID coefficient self-tuning strategy with improved genetics algorithm, this method can optimize calculation speed and parameters[4]. DE Xiang yi gave PID coefficient self-tuning of fuzzy prediction model, fuzzy control algorithm solved uncertain factor question, prediction model was used to evaluate future deviation, its regulation time was less and control precision was higher [5]. Zhang Shi feng presented controller design of PID coefficient self-tuning based on neural network, neural network was added to controller to compute PID coefficient[6], these thesises were focus on independent calculation of PID coefficient and effect for PID control. some disadvantages of digital PID were still existed, complex calculation of coefficient self-tuning, and poor control effect for variable target, In order to emit shortcoming of digital PID, neural network structure PID is presented and calculated in real time based on microprocessor, finally real test is made to verify application effect.

\section{Neural Network Structure PID}

PID control is the most common method in the industry control, it can keep better robustness and reliability with simple and easy using, and it is used by engineer to regulate system without complex algorithm, The control output of digital PID is calculated as followed,

$$
\mathrm{u}(\mathrm{t})=\mathrm{K}_{\mathrm{p}}\left[e(t)+\frac{1}{T_{I}} \int_{0}^{t} e(t) d t+\frac{T_{d} d e(t)}{d t}\right]
$$


Where, $K_{p}$ is proportional coefficient, $T_{I}$ is integral time constant, $T_{D}$ is differential time constant.

Correction part function of PID controller is followed,(1) Proportional part is reflected deviation signal $e(t)$ of system in real time, when deviation is formed, controller quickly gave control measurement to decrease bias.(2) Integral part is used to emit static deviation to increase indiscrimination degree. Integral action Strength is depended on integral time coefficient $\mathrm{T}_{\mathrm{I}}$, the bigger $T_{I}$ is, the poorer integral action is, vice versa.(3) Differential part reflected change trend of deviation signal, and before the error signal became larger, an early effective verification signal is introduced into system in order to increase action speed of system and decrease regulation time.

Digital PID algorithm can fulfill optimal control for single target, it is difficult to meet fast and stable requirement of fine control in the condition of multi-target. Neural network has reception and remembering function and high robustness, neural network structure PID algorithm combined digital PID control algorithm with neural network, PID control algorithm is made by forward algorithm of network, PID coefficient self adapt adjustment is made by backward algorithm of network[7], PID coefficient is automatically adjusted.

Neural network structure PID consisted of input lay, hidden lay and output lay and other different neural unit, as shown in figure 1. The two neural units of input lay are control target $r$ and output value $\mathrm{y}$, there are three neural units in hidden lay, different output function are used to these neural units corresponding to proportional part, integral part, and differential part, there is only one neural unit in output lay, that is output $\mathrm{u}$ of PID, when target and learning error is given, PID with well-training neural network can automatically modify network weight value, meditated controlled object to approach target value. Its mathematic formula is followed.

In input lay, input is

$$
\begin{aligned}
& v_{1}(k)=r(k), \\
& v_{2}(k)=y(k), \\
& x_{i}=v_{i}(k), i=1,2,
\end{aligned}
$$

output is

In hidden lay, input is

$$
v_{i}^{\prime}(k)=\sum_{i=1}^{2} w_{i j} x_{i}(k), j=1,2,3 .
$$

output is

$$
\begin{aligned}
& \text { Proportional } x_{1}^{\prime}(k)=v_{1}^{\prime}(k), \\
& \text { Integral } x_{2}^{\prime}(k)=x_{2}^{\prime}(k-1)+v_{2}^{\prime}(k), \\
& \text { Differential } x_{3}^{\prime}(k)=v_{3}^{\prime}(k)-v_{3}^{\prime}(k-1) .
\end{aligned}
$$

In output lay, input is

$$
v_{h}^{\prime \prime}(k)=\sum_{j=1}^{3} w_{j h}^{\prime} x_{j}^{\prime}(k), h=1 \text {. }
$$

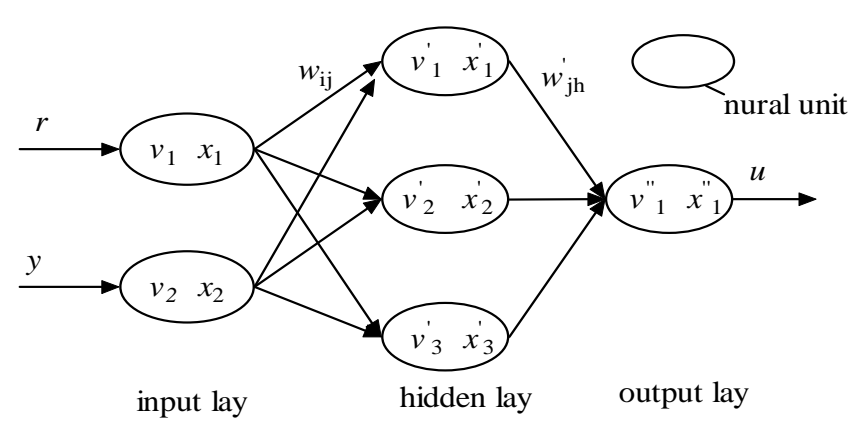

Fig.1 Neural network structural PID

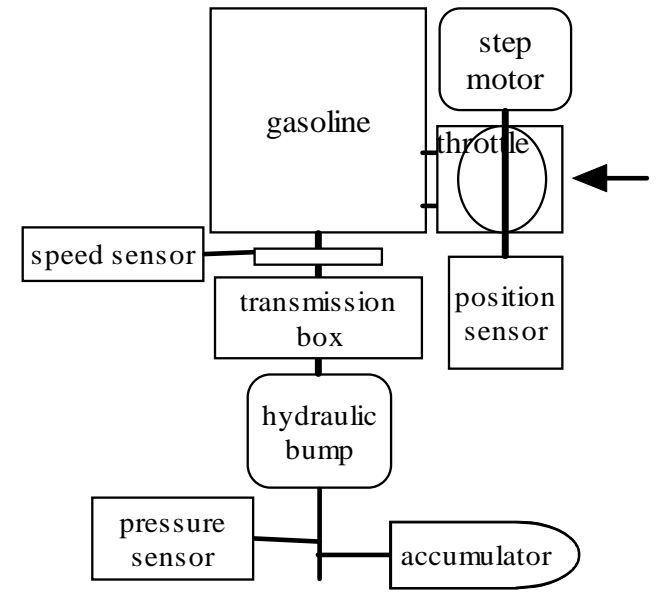

Fig.2 Structure of power system 
output is

$$
u=x_{1}^{\prime \prime}=v_{h}^{\prime \prime}(k) \text {. }
$$

Flow frame of neural network structure PID algorithm is followed.

(1) Initial condition $e=r-y$, weighty value $\mathrm{w}_{1 \mathrm{j}}(0) 、 \mathrm{w}_{2 \mathrm{j}}(0)$ are set.

(2) Learning step and learning error is given.

(3) System control target is given.

(4) Control target $r$ is compared with output value $y$, network weight value w can be modified

(5) Output value u of PID is determined.

\section{Control Requirement of Power system}

Hydraulic walking platform (HWP) is made up of power system, junction structure, hydraulic pressure system, electronic control system, sense system and top controller. Foreign gasoline with two strokes and single cylinder is chosen as power resource, as shown in figure 2. Electric controlled throttle valve and electric control system are added to this gasoline engine, transmission box is used to connect gasoline and bump with transmission ration $4: 1$, hydraulic pump provided fluid pressure to system line.The technical parameter of small type gasoline and hydraulic bump is: gasoline power 20kW, Max torque17.5N·m, Max.speed16000r/min, bump power 7.5/kW, Max torque $35 \mathrm{~N} \cdot \mathrm{m}$,Max speed $3600 \mathrm{r} / \mathrm{min}$, Work principle of power system is followed: gasoline engine provided power to hydraulic bump, and make hydraulic bump rotate, variable bump continued to adjust flow rate according to gait condition and burden weight change in order to keep hydraulic pressure stable. Electronic control system automatically mediated throttle position in real time, so control requirement of HWP is followed:(1)Throttle position is regulated quickly to output power when external load is transient change.(2) Since large range of throttle position and rotation speed are bigger, these target is multiple and is demanded to precision regulation. (3) Accuracy and response time of rotation speed is in $\pm 150 \mathrm{r} / \mathrm{min}$ and within $100 \mathrm{~ms}$ respectively.

\section{Simulation and Test}

\subsection{Target rotation speed}

Hydraulic walking platform is operated in four walking gait: standing, stepping, slow walking and fast walking, input power demanded to each walking is different, target rotation speed of gasoline engine is made, as shown in table 3.

Tab.2 Target rotation speed of engine in different gait

\begin{tabular}{ccccc}
\hline & $\begin{array}{c}\text { Stand } \\
\text {-ing }\end{array}$ & $\begin{array}{c}\text { Step } \\
\text {-ing }\end{array}$ & $\begin{array}{c}\text { Slow } \\
\text { walking }\end{array}$ & $\begin{array}{c}\text { Fast } \\
\text { walking }\end{array}$ \\
\hline $\begin{array}{c}\text { Power } / \mathrm{kW} \\
\begin{array}{c}\text { Rotation speed } \\
/ \mathrm{r} \cdot \mathrm{min}^{-1}\end{array}\end{array}$ & 5 & 7.5 & 10.5 & 15.7 \\
\hline
\end{tabular}

\subsection{Simulation Comparison}

In the Matlab/simulink simulation environment, control model of traditional PID and N-PID is found respectively, in the condition of sample time $1 \mathrm{~ms}$, target speed $10000 \mathrm{r} / \mathrm{min}$, different steps and learn error is selected in the N-PID model, control effect of different step is shown in table 3, with the learning error decreasing, learning steps become more, control time needed is longer, but speed vibration range is small, when learning error is less in 0.06 , speed vibration range is in $150 \mathrm{r} / \mathrm{min}$.

According to set learning error, PID coefficient is given after learning in N_PID model, speed control effect is shown in figure 3, curve 1 corresponding to 160 steps is better than curve 2 of 50 steps. Control time of curve 1 for different target is shorter than that of curve 3 with traditional PID $\mathrm{K}_{\mathrm{p}}=45, \mathrm{~K}_{\mathrm{I}}=8, \mathrm{~K}_{\mathrm{D}}=0.8$. 


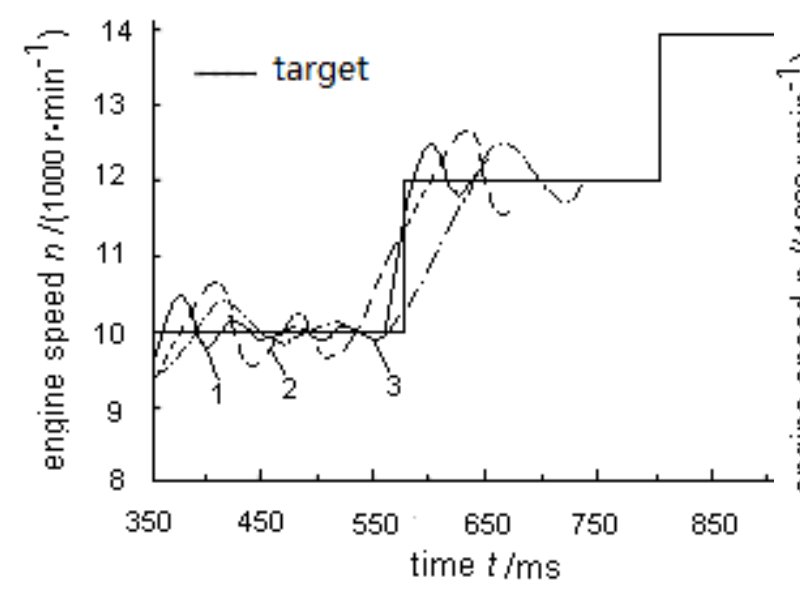

Fig.3 Control effect of variable rotation speed target

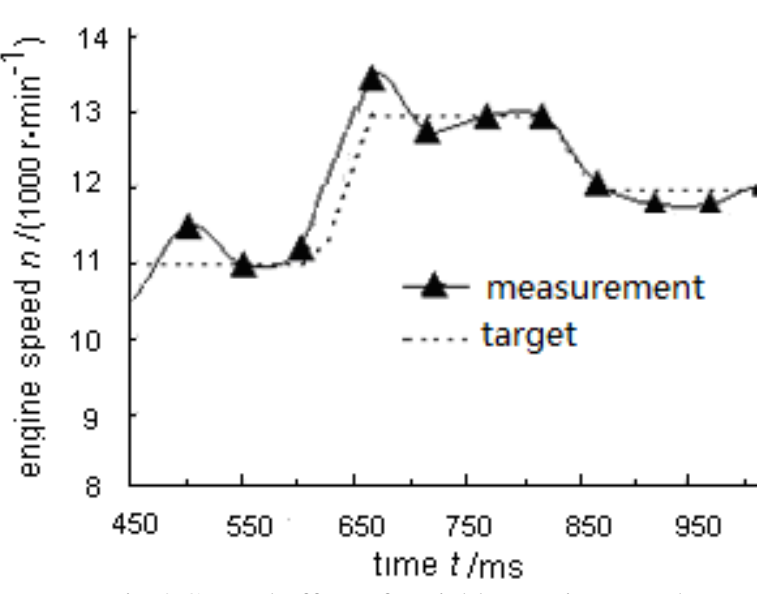

Fig.4 Control effect of variable rotation speed target

\subsection{Control Test}

Electronic controlled unit is developed with digital signal microprocessor DSP56F807, N-PID model procedure is downloaded in DSP56F807 to fulfill N-PID algorithm, different speed target is input and control effect is displayed in monitor computer. PID coefficient is automatically calculated by neural network structure PID algorithm, 50ms sample period is given, speed mediation effect by control system is shown in figure 4 after the $450 \mathrm{~ms}$ sample time, dashed line is indicated rotation speed target, and real line is real measurement speed. Seen from figure 4, real rotation speed is well traced to target value, transitional change time is short, super regulation value is small, all this showed that control effect of variable target in rotational speed is good.

\section{Conclusion}

1) Control algorithm of neural network structure PID is presented, neural network structure with three lays and its mathmatic fomula and flow frame of network training are gave, it simplified PID coefficient self-tuning.

2) Simulation comparison between neural network structure PID and traditional PID is made, well-training neural network can quickly finish multi-target approaching and needn't compute PID coefficient. Test results showed that control effect of neural network structure PID algorithm is stable, and it can meet the design requirement in transient speed control.

\section{Acknowledgements}

This work was financially supported by the National Natural Science Foundation (51305457).

\section{Reference}

[1] Siegwart R, Nourbakhsh I. R. XiAN: Shanghai Jiaotong University Press, 2006.

[2] CHEN Xuedong, Song Yu, Jia Wen chuan. WU Han: Huazhong University of Science and Technology Press, 2006. (in Chinese)

[3] LIU Dao.University of South China. 2012 (in Chinese)

[4] LI Rui xia, Li Fen xia. Mechanical Engineering \& Automation. 2008,(06): 56-59 (in Chinese)

[5] DE Xiang yi. Northeastern University. 2008 (in Chinese)

[6] ZHANG Shi feng, Li Peng..Automation\&instrument.2009, 30(7):64-66.

[7] LIU Jin kun. Beijing: Electricity Industry Press,2003. 